\title{
PERCOBAAN KEDOKTERAN TERHADAP HEWAN HIDUP DALAM PERSPEKTIF HUKUM ISLAM
}

\section{MEDICAL EXPERIMENT ON LIVING ANIMALS IN ISLAMIC LAW PERSPECTIVE}

\author{
M. Kasim \\ Sekolah Tinggi Ilmu Islam dan Bahasa Arab (STIBA) Makassar \\ Email: qasimsaguni@gmail.com \\ Farida Aprianti \\ Sekolah Tinggi Ilmu Islam dan Bahasa Arab (STIBA) Makassar \\ Email: farida_aprianti@stiba.ac.id

\section{Sa'adal Jannah} \\ Sekolah Tinggi Ilmu Islam dan Bahasa Arab (STIBA) Makassar \\ Email: saadaljannah@stiba.ac.id \\ Nurayu Rezki \\ Sekolah Tinggi Ilmu Islam dan Bahasa Arab (STIBA) Makassar \\ Email: nurayurezki99@gmail.com
}

\begin{tabular}{|c|c|}
\hline Keywords : & ABSTRACT \\
\hline $\begin{array}{l}\text { Medicine, live animals, Islamic } \\
\text { law }\end{array}$ & $\begin{array}{l}\text { This study aims to determine the legal experimental medicine on live } \\
\text { animals from the perspective of contemporary fiqh, as well as to find out } \\
\text { the opinions of the scholars in understanding the problem. This research } \\
\text { uses descriptive qualitative research (non-statistical) which focuses on } \\
\text { the study of manuscripts and texts using a normative juridical approach. } \\
\text { The results of the study found that some scholars allowed the use of } \\
\text { animals in an experiment. However, some scholars do not allow its use } \\
\text { without knowing the ethics in experiments. The reason is that this never } \\
\text { existed in the health sector at the time of the Prophet Muhammad. } \\
\text { However, if the user is carried out without an urgent need, then the law } \\
\text { is not allowed. }\end{array}$ \\
\hline \multirow{2}{*}{$\begin{array}{l}\text { Kata kunci : } \\
\text { Kedokteran, Hewan Hidup, } \\
\text { Hukum Islam }\end{array}$} & ABSTRAK \\
\hline & $\begin{array}{l}\text { Penelitian ini bertujuan untuk mengetahui hukum percobaan kedokteran } \\
\text { terhadap hewan hidup dalam perspektif fikih kontemporer, serta } \\
\text { mengetahui pendapat para ulama dalam memahami masalah tersebut. } \\
\text { Penelitian ini menggunakan jenis penelitian kualitatif deskriptif (non- } \\
\text { statistik) yang terfokus pada studi naskah dan teks dengan menggunakan } \\
\text { pendekatan yuridis normatif. Hasil penelitian ditemukan bahwa } \\
\text { sebagian ulama membolehkan penggunaan hewan dalam suatu } \\
\text { percobaan. Namun, sebagian ulama tidak membolehkan penggunaannya } \\
\text { tanpa mengetahui etika dalam percobaan. Alasannya bahwa hal ini } \\
\text { pernah ada di bidang kesehatan pada masa Rasulullah saw. Adapun jika } \\
\text { penggunaannya dilakukan tanpa ada kebutuhan yang mendesak, maka } \\
\text { hukumnya tidak diperbolehkan. }\end{array}$ \\
\hline
\end{tabular}




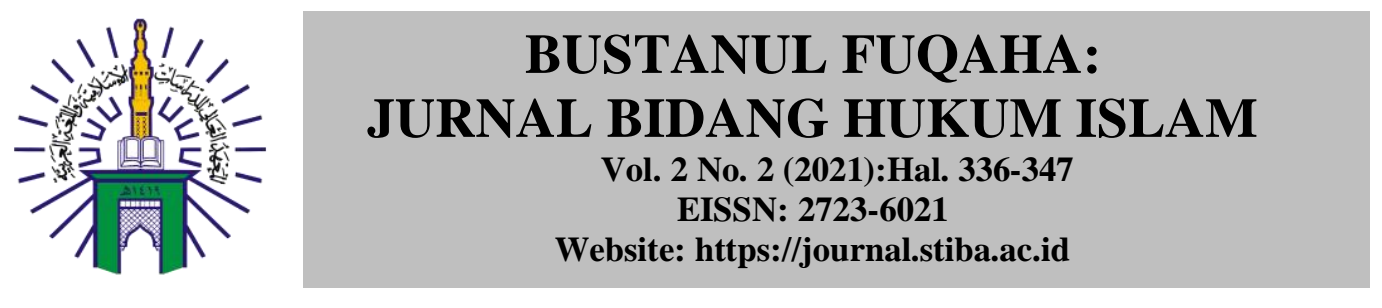

\section{BUSTANUL FUQAHA}

Jurnal Bidang Hukum Islam

Diterima: 13 Agustus 2021; Direvisi: 18 Agustus 2021; Disetujui: 18 Agustus 2021; Tersedia online: 20 Agustus 2021

How to cite: M. Kasim, Farida Aprianti, Sa'adal Jannah, Nurayu Rezki, "Percobaan Kedokteran terhadap Hewan Hidup dalam Perspektif Hukum Islam", BUSTANUL FUQAHA: Jurnal Bidang Hukum Islam 2, No. 2 (2021): 336-347. doi: 10.36701/bustanul.v2i2. 373.

\section{PENDAHULUAN}

Hewan adalah salah satu dari berbagai makhluk hidup di muka bumi ini. Ia merupakan suatu kelompok organisme yang diklasifikasikan dalam kerajaan animalia atau metazoan, dan sebutan lainnya adalah fauna dan margasatwa ${ }^{1}$. Hewan dalam pengertian sistematika modern mencakup hanya kelompok bersel banyak (multiselural) dan terorganisasi dalam fungsi-fungsi yang berbeda. Hewan berperan penting dalam penelitian dan percobaan, yang merupakan bahan utama dalam sebuah percobaan. Hewan yang sering digunakan dalam percobaan adalah tikus dan $\mathrm{mencit}^{2}$, karena hewan ini memiliki berbagai kesamaan organ pada tubuh manusia, atau sifat-sifat khusus yang berguna untuk keperluan penilitian ilmiah ${ }^{3}$. Sehingga, hewan sering kali dijadikan dalam percobaan penelitian untuk mengetahui suatu hasil eksperiman, dengan cara menggunakan senyawa organik yang akan dimasukkan ke dalam tubuh hewan, melalui induksi senyawa kimia (diabetogenik) misalnya dengan streptosotosin, aloksan asam dehidroaskorbat, asam dialurat, asam ksanturenat; induksi virus, ataupun secara genetika ${ }^{4}$. Hal ini kemungkinan besar akan menimbulkan efek samping (mudarat) bagi hewan itu sendiri, bahkan membuat hewan itu mati, padahal hewan adalah makhluk hidup yang memiliki hak untuk kelangsungan hidupnya, dan tentunya merupakan ciptaan Allah swt.

Hewan dalam pandangan Islam menuai dilema tatkala ihwal kebolehan dalam mengorbankan organ tubuhnya untuk dibedah atau diteliti demi kemaslahatan manusia. Hal ini sering disebut sebagai hewan percobaan, di mana hewan yang dipergunakan pada sebuah penelitian biologis dan biomedik yang dipilih berdasarkan syarat dan standar dasar yang diperlukan dalam penelitian. Adapun pelaksanaannya, penggunaan hewan percobaan untuk penelitian, maka diperlukan seperangkat pengetahuan yang cukup memadai mengenai berbagai aspek tentang sarana biologis, dan dalam hal penggunaan hewan model laboratorium. Pengelolaan hewan model penelitian sejatinya dimulai dengan proses pengadaan hewan yang mengikuti proses seleksi jenis hewan yang cocok terhadap materi peneliti. Manusia dan hewan memiliki beberapa persamaan penyakit, sehingga hewan dapat bertindak sebagai model atau studi penyakit manusia, yang mana memungkinkan para peneliti untuk mengeksplorasi terapi potensial dengan cara yang tidak akan mungkin dilakukan pada manusia. Untuk itu, dalam mempelajari mekanisme

\footnotetext{
${ }^{1}$ Yunanda, Rifki. Fauna dalam Perspektif Al-Qur'an (Studi Tafsir Ilmi Kemenag LIPI). Diss. UIN Raden Intan Lampung, 2019. h. 18.

${ }^{2}$ Agung Endro Nugroho. "Hewan percobaan diabetes mellitus: patologi dan mekanisme aksi diabetogenik." Biodiversitas 7.4 (2006), h. 378.

${ }^{3}$ Marcellino Mardanung Setijono. "Mencit (Mus musculus) sebagai hewan percobaan." (1985).

${ }^{4}$ Agung Endro Nugroho. "Hewan percobaan diabetes mellitus: patologi dan mekanisme aksi diabetogenik." Biodiversitas 7.4 (2006), h. 382.
} 


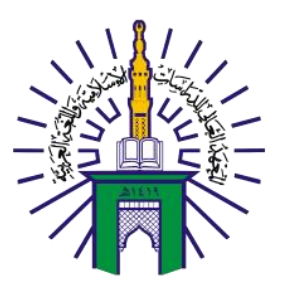

\section{BUSTANUL FUQAHA: \\ JURNAL BIDANG HUKUM ISLAM \\ Vol. 2 No. 2 (2021):Hal. 336-347 \\ EISSN: 2723-6021 \\ Website: https://journal.stiba.ac.id}

penyakit pada hewan, maka ia diarahkan langsung pada pengembangan teknologi baru dan obat-obatan yang bermanfaat bagi manusia 5 .

Atas dasar dilema tersebut, maka upaya pengkajian terhadap percobaan hewan dalam dunia kedokteran dari sudut pandang hukum Islam adalah menjadi sesuatu yang penting. Untuk itu, agar lebih fokus, penulis membatasi ruang lingkup kajian pada: 1) upaya penelusuran jenis-jenis hewan hidup yang dapat dipilih sebagai bahan percobaan kedokteran; 2) upaya pengkajian perspektif hukum Islam terhadap proses penggunaan hewan sebagai bahan percobaan kedokteran. Dengan demikian, pengkajian ini berarahtujuan bertujuan untuk mengetahui peran penting hewan dalam percobaan kedokteran, dan tentunya untuk mengetahui hukum Islam dalam pandangan para ulama dalam percobaan kedokteran terhadap hewan hidup.

Penelitian ini menggunakan metode penelitian kualitatif dengan teknik studi kepustakaan (library research) melalui pendekatan historis, yuridis-normatif dan filosofis. Berkenaan dengan kajian ini, telah didapati oleh penulis beberap kajian terdahulu yang relevan di antaranya: 1) Penelitian yang berjudul "Pandangan Aksiologi terhadap Bioetika dalam Memanfaatkan Hewan Coba (Animal Research) di Laboratorium. Hasil penelitian ini mengungkap bahwa etika adalah induk dari bioetika, di mana sebagai fokus bioetika adalah upaya dalam menyelidiki dimensi etis dari masalah-masalah teknologi dan makhluk hidup yang terkait dengan penerapannya dalam kehidupan, dan itu etis baik secara peraturan nasional maupun internasional ${ }^{6}$; 2) Penelitian yang berjudul "Etika Pemanfaatan Hewan Percobaan dalam Penelitian Kesehatan." Hasil penelitian ditemukan bahwa penelitian dengan hewan percobaan harus memperhatikan aspek perlakuan manusiawi terhadap hewan-hewan tersebut, sesuai dengan prinsip 5F (Freedom) yaitu: bebas dari rasa lapar dan haus, bebas dari rasa tidak nyaman, bebas dari rasa nyeri, trauma, dan penyakit, bebas dari ketakutan dan stres jangka panjang, bebas mengekspresikan tingkah laku alami, diberiksn ruang dan fasilitas yang sesuai (pengayaan lingkungan yang sesuai). Seluruh perlakuan terhadap hewan percobaan dituangkan secara rinci di dalam protokol penelitian yang dianalogikan sebagai informed consent pada penelitian yang menggunakan relawan manusia ${ }^{7}$. Adapun pengkajian yang berkaitan dengan pemanfaatan hewan percobaan dalam sudut pandang Islam, maka sampai saat ini belum ditemukan. Dengan demikian, kebaruan dari upaya pengkajian ini akan memperkaya kajian Islamic studies dan bermanfaat bagi dokter muslim secara khusus, serta umat dan bangsa.

\footnotetext{
${ }^{5}$ Shahdevi Nandar Kurniawan,dkk., Penggunaan Hewan Coba pada Penelitian di Bidang Neurologi, Cet 1; JL.Veteran 10-11 Malang 65145 Indonesia Gedung INBIS 1.t.3. 2018.

6 Jumrodah, "Pandangan Aksiologi terhadap Bioetika dalam Memanfaatkan hewan Coba (Animal Research) di Laborstorium” JURNAL IAIN PALANGKARAYA 2, No. 1 (Februari, 2017)

${ }^{7}$ Endi Ridwan, "Etika Pemanfaatan Hewan Percobaan Penelitian Kesehatan" J Indon Med Assoc. 63, no. 3 (Maret, 2013)
} 


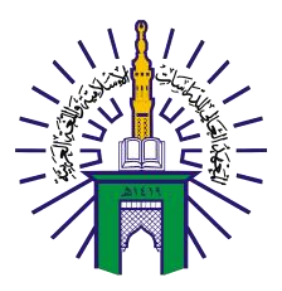

\section{BUSTANUL FUQAHA: \\ JURNAL BIDANG HUKUM ISLAM \\ Vol. 2 No. 2 (2021):Hal. 336-347 \\ EISSN: 2723-6021 \\ Website: https://journal.stiba.ac.id}

\section{PEMBAHASAN}

\section{Dasar-Dasar Penelitian Hewan dalam Dunia Kedokteran \\ Pemanfaatan Hewan dalam Pengujian dan Model Penyakit Manusia}

Hewan memiliki peran penting dalam dunia kedokteran, terutama membantu para peneliti dalam pemahaman penyakit serta pengembangan pengobatan yang efektif. Pamungkas et al. mengatakan bahwa penelitian dengan melibatkan pemanfaatan hewan terbukti telah menjadi landasan yang baik bagi pengembangan dan kemajuan bidang ilmu medis ${ }^{89}$. Hewan percobaan dalam laboratorium juga berkontribusi dalam memberikan informasi penting berkaitan dengan sistem kehidupan yang kompleks, mulai dari sel, jaringan dan organ.

Hewan secara biologis memiliki kemiripan dengan manusia dalam banyak hal dan mereka memiliki kerentanan terhadap ratusan penyakit manusia. Hal ini menjadikan hewan sebagai model yang efektif dalam mempelajari penyakit manusia, dan upaya untuk menemukan obat terhadap suatu penyakit ${ }^{10}$. Selain berkontribusi dalam pemahaman kita tentang penyakit, melalui penggunaan model hewan sangat memungkinkan untuk mengeksprolasi potensi terapi dengan cara yang tidak mungkin dilakukan pada manusia. Hal ini ditengarai akan kemampuan hewan untuk berinteraksi dan bereaksi terhadap rangsangan, memberikan pemahaman peneliti tentang bagaimana suatu komponen obat sebagai contoh dapat bergerak di dalam tubuh manusia serta memberi rangsangan terhadap target sel atau organ. Adapun mayoritas hewan yang digunakan oleh peneliti terfokus pada pengkajian pengobatan dan pencegahan penyakit, serta pengobatan cedera $^{11}$. Sehingga, hewan ini memberikan sumbangsih yang cukup banyak dalam penelitian medis dasar bagi manusia dan hewan, penangkaran dan diagnosis.

\section{Satwa Primata sebagai Hewan Model Studi Biologi dan Kanker Payudara}

Kanker payudara merupakan kanker dengan tingkat kejadian dan kematian tertinggi pada wanita di seluruh dunia. Meskipun saat ini telah ditemukan beberapa metode pengobatan terhadap kanker payudara, masih diperlukan berbagai pengobatan terhadap kanker payudara, masih diperlukan sebagai pendekatan untuk menemukan metode pencegahan yang efektif demi menekan tingkat kejadian penyakit ini ${ }^{12}$. Dalam satu dekade terakhir, hasil penelitian mengindikasikan bahwa kondisi lingkungan (termasuk nutrisi dan makanan) pada masa pertumbuhan mempengaruhi "Epigenetic programming"

8 Winoto, Imelda L. "Penanganan dan Pengendalian Hewan Laboratorium." Jurnal Ilmiah Veteriner Nasional 13 (2014), h. 108.

${ }^{9}$ Pamungkas, Joko, Diah Iskandriati, Maryati Surya, \& Dondin Sajuthi. "Peran Komisi Etik dalam Kegiatan Penelitian, Pengujuan dan Pendidikan." Jurnal Ilmiah Veteriner Nasional 13 (2014): 107.

${ }^{10}$ Nainu, Firzan. "Penggunaan Drosophila melanogaster sebagai organisme model dalam penemuan obat." Jurnal Farmasi Galenika (Galenika Journal of Pharmacy)(e-Journal) 4.1 (2018): 50-67.

${ }^{11}$ Diah Iskandriati, Dondin Sajuthi, \& Joko Pamungkas. "Pemanfaatan Hewan dalam Pengujuan dan Model Penyakit Manusia." Jurnal Ilmiah Veteriner Nasional 13 (2014), h. 112.

${ }^{12}$ Naïf Mohammad, Islam perduli terhadap satwa( cet;1, Malang 2010). h. 13 
yang secara jangka panjang menemukan berbagai resiko penyakit di usia dewasa. Hal ini dikenal dengan teori developmental originis of health and diseases $(D O H A D)^{13}$.

Secara spesifik, untuk organ payudara, kondisi pada fase-fase penting perkembangan kelenjar susu memiliki efek jangka panjang terhadap resiko kanker. Dalam upaya penekanan resiko kanker payudara, diperlukan eksplorasi potensi bahan alami yang dapat mempengaruhi kelenjar payudara, eksplorasi tersebut akan meliputi pendekatan in-vitro serta in-vivo pada hewan coba yang sesuai dan terjustifikasi dengan baik. Sampai saat ini hewan rodentia telah menjadi hewan model yang sangat bermanfaat bagi kemajuaan teknologi untuk penelitian kanker payudara. Satwa primata, khususnya Macaca Fascicularis, merupakan hewan model yang relatif ideal bagi penelitian biomedis, tidak terkecuali bagi kanker payudara ${ }^{14}$.

\section{Hewan Sebagai Objek Percobaan dalam Kedokteran}

\section{Cara bekerja dengan hewan percobaan}

Setiap orang, baik praktikan maupun peneliti yang bekerja di labolatorium yang menggunakan hewan percobaan hendaknya membaca dan memperhatikan: 1) Petunjuk memelihara dan menggunakan hewan percobaan; 2) Dasar-dasar pemeliharaan hewan percobaan. Hal ini dikarenakan hewan percobaan perlu diperlakukan dengan rasa kasih sayang. Adapun contoh cara memperlakukan hewan percobaan, semisal: a) kelinci dan marmot, jangan sekali-kali memegang telinga kelinci karena saraf dan pembuluh darah dapat terganggu; b) tikus dan mencit, peganglah pada ekornya, tetapi hati-hati jangan sampai hewan tersebut membalikkan tubuhnya dan menggigit Anda karena itu selain ekornya, pegang juga bagian leher belakang (kulit tengkuk) dengan ibu jari dan jari telunjuk ${ }^{15}$.

Ketika hendak menggunakan kembali hewan yang telah digunakan, dan untuk menghemat biaya, bila memungkinkan, maka diperbolehkan menggunakan hewan percobaan tersebut lebih dari sekali. Walaupun demikian, jika hewan tersebut telah digunakan dalam satu periode dan obat yang digunakan pada percobaan sebelumnya masih berada dalam tubuh hewan kemungkinan hasil percobaan berikutnya akan memberikan data yang tidak benar. Hal ini terutama terjadi pada kasus pemberiaan barbiturat yang menyebabkan induksi enzim. Dengan dalil ini maka hewan percobaan tersebut baru boleh digunakan untuk percobaan berikutnya setelah selang waktu minimal 14 hari, disamping itu kelinci harus digunakan sebagai alternatif untuk cara pemberian internal, maupun eksternal, meskipun percobaan menjadi berurutan dalam melakukan $\operatorname{percobaan}^{16}$.

\footnotetext{
${ }^{13}$ Fitriya N Dewi, \& J Mark Cline. "Satwa Primata sebagai Hewan Model Studi Biologi dan Kanker Payudara." Jurnal Ilmiah Veteriner Nasional 13 (2014), h. 114.

${ }^{14}$ Fitriya N Dewi, \& J Mark Cline. "Satwa Primata sebagai Hewan Model Studi Biologi dan Kanker Payudara." Jurnal Ilmiah Veteriner Nasional 13 (2014), h. 114.

${ }^{15}$ Kurniawan, Shahdevi Nandar, and Neila Raisa. Penggunaan Hewan Coba pada Penelitian di Bidang Neurologi. Universitas Brawijaya Press, 2018.

${ }^{16}$ Shahdevi Nandar, Kurniawan, and Neila Raisa. Penggunaan Hewan Coba pada Penelitian di Bidang Neurologi. Universitas Brawijaya Press, 2018.
} 


\section{Memberikan kode hewan}

Sering kali diperlukan untuk mengidentifikasi hewan yang terdapat dalam satu kelompok atau kandang, sehingga hewan-hewan percobaan perlu sekali diberi kode. Gunakan larutan 10\% asam pitrat dalam air dan sebuah sikat atau kuas. Punggung hewan dibagi menjadi tiga bagian: 1) Bagian kanan menunjukan angka satuan; 2) Bagian tengah menunjukkan angka puluhan; dan 3) Bagian tengah menunjukkan angka ratusan ${ }^{17}$.

Hal yang perlu diperhatikan dengan cermat dan teliti terhadap hewan percobaan agar memperoleh hasil yang maksimal dalam sebuah penelitian adalah menerapkan kaidah kesejahteraan hewan. Menurut Mutiarahmi et al. mengatakan bahwa hewan percobaan terutama secara etis, seorang peneliti harus menerapkan prinsip replacement, reduction, dan refinement (3R), serta prinsip lima kebebasan hewan yaitu (1) bebas dari rasa lapar dan haus, (2) bebas dari rasa tidak yaman, (3) bebas dari rasa nyeri, luka dan penyakit, (4) bebas dari rasa takut dan stres, dan (5) bebas untuk engekspresikan tingkah laku alamiah $^{18}$.

\section{Ukuran Tingkat Ketidaksadaran}

Cara yang sering dilupakan untuk mengukur tingkat ketidaksadaran dan kemampuaan untuk merasakan nyeri adalah refleks pabpebra, kornea dan kedip. Refleks ini dinilai dengan cara menyentuh kelopak mata hewan atau korneanya, hilangnya refleks kedip menunjukkan ketidaksadaran, dengan demikian kurang peka terhadap rasa nyeri (kecuali pada penggunaan obat bentuk curare, yang sengaja diberikan untuk melumpuhkan otot atau anestesi disosiatif yang menggunakan kloral hidrat atau ketamine hidroklorida, dll.). Pada hewan dalam keadaan tak sadar atau tak peka terhadap perasaan nyeri, gambaran elektroense falogram terlihat datar atau isoelektrik. Untuk memastikan kematiaan hewan diperlukan penghentiaan aliran darah ke otak, jadi denyut jantung harus berhenti, tidak seperti pada manusia, walaupun denyut jantung menetap untuk beberapa lama, asalnya refleks konea tak ada atau elektroense falogram rata, hewan sudah dianggap mati, pastikan dahulu bahwa pada hewan yang dibunuh tak terjadi recovery, sebelum membuang hewan. Penting sekali dipastikan bahwa denyut jantung telah berhenti, tak adanya aktivitas atau pergerakan otot yang dapat digunakan sebagai pedoman dari ketidaksadaran atau ketidakpekaaanya terhadap rangsangan rasa sakit, walaupun tak adanya pergerakan yang lama menunjukkan hewan mati ${ }^{19}$.

\section{Pandangan Islam terhadap Hewan}

Manusia sebagai pemimpin di bumi "Kholifatul Fi al-Ardhi" mempunyai beberapa wewenang dan tanggung jawab yang diberikan oleh Allah swt., Nabi dan Rasul sebagai Penyampai risalah dari Allah swt. mempunyai misi agar seluruh umat manusia bisa mempergunakan wewenang tersebut dengan benar dan memberikan informasi bahwa

\footnotetext{
${ }^{17}$ Shahdevi Nandar, Kurniawan, and Neila Raisa. Penggunaan Hewan Coba pada Penelitian di Bidang Neurologi. Universitas Brawijaya Press, 2018.

${ }^{18}$ Citra Nur, Mutiarahmi, Tyagita Hartady, and Ronny Lesmana. "Kajian Pustaka: Penggunaan Mencit Sebagai Hewan Coba di Laboratorium yang Mengacu pada Prinsip Kesejahteraan Hewan." Jurnal Indonesia Medicus Veterinus 10 (2021).

${ }^{19}$ Shahdevi Nandar, Kurniawan, and Neila Raisa. Penggunaan Hewan Coba pada Penelitian di Bidang Neurologi. Universitas Brawijaya Press, 2018.
} 


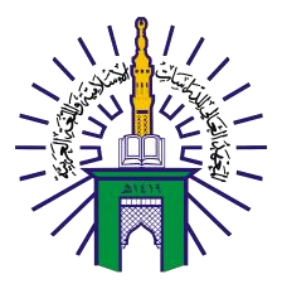

\section{BUSTANUL FUQAHA: \\ JURNAL BIDANG HUKUM ISLAM \\ Vol. 2 No. 2 (2021):Hal. 336-347 \\ EISSN: 2723-6021 \\ Website: https://journal.stiba.ac.id}

wewenang mereka akan diminta pertanggungjawaban kelak di yaumil akhir (hari kiamat). Oleh karena itu, manusia mempunyai wewenang untuk memanfaatkan hasil bumi serta segala sesuatu yang hidup di atasnya seperti tumbuh-tumbuhan dan binatang yang telah disediakan secara gratis oleh Allah swt., maka mausia mempunyai hak untuk memanfaatkannya ${ }^{20}$. Namun, yang perlu diingat adalah manusia juga harus bertanggung jawab dan tetap memeliharanya, pemanfaatan tersebut bukan berarti bahwa manusia boleh memanfaatkan sekehendak hatinya, namun perlu pemanfaatan yang bertanggung jawab dan berkelanjutan. Terdapat beberapa ayat Al-Qur'an yang menjadi dalil tentang hal tersebut di antaranya:

1. Qs. Al-Baqarah, 2:29,

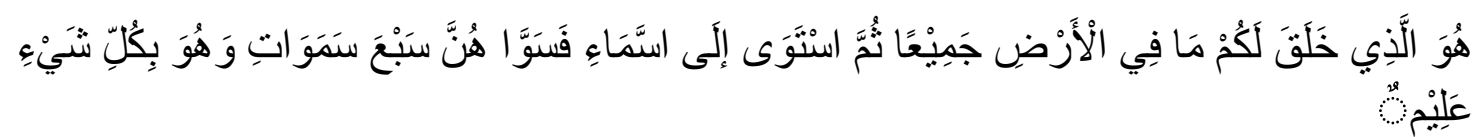

Terjemahnya:

"Dialah Allah, yang menjadikan segala yang ada di bumi untuk kamu dan dia berkehendak (menciptkan) langit, lalu dijadikan-Nya tujuh langit. dan Dia Maha Mengetahui segala sesuatu"21.

2. Qs. Al-Jasiyah, 45:13,

Terjemahnya:

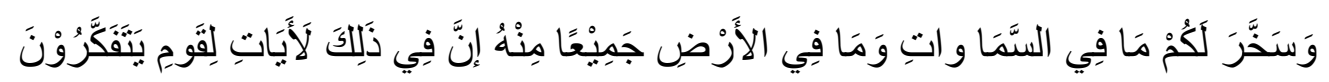

"Dan Dia telah menundukkan untukmu apa yang di langit dan apa yang di bumi semuanya, (sebagai rahmat) dari pada-Nya. Sesungguhnya pada yang demikian itu benar-benar terdapat tanda-tanda (kekuasaan Allah) bagi kaum yang berpikir""22.

Dari beberapa ayat di atas ditinjau dari segi Tafsir bil Ma'sur maupun Tafsir Birra'yi, semuanya membenarkan akan kenyataan bahwa sesungguhnya manusia berhak memanfaatkan semua yang diciptakan oleh Allah swt. selama untuk kemaslahatan umat manusia, dan salah satu dari hak tersebut adalah hak untuk memanfaatkan tumbuhtumbuhan dan hewan.

\section{Islam Melarang Menyakiti Satwa/Binatang.}

Dalam ajaran Islam (syariah) mengenai hak asasi satwa disebutkan secara detail dan jelas, hukum yang berlaku adalah kerusakan atau perusakan akibat dendam akibat terkena kerusakan itu dilarang, dalilnya berbunyi, لا ضرر ولا ضرار. Kisah Nabi-nabi terdahul pun mencerminkan bahwa Islam sangat peduli dan memiliki kasih sayang terhadap binatang, di dalam Al-Qur'an terdapat kisah populer tentang Nabi Sulaiman Alaihisalaam yang

\footnotetext{
${ }^{20}$ Mohammad Na'fi, Islam Peduli Terhadap Satwa, h.12

${ }^{21} \mathrm{https}$ ///tafsirq.com/2-al-baqarah/ayat-29 (Diakses 18/08/2021)

$22 \mathrm{https} / / /$ tafsirq.com/45-al-jasiyah/ayat-13 (Diakses 18/08/2021)
} 


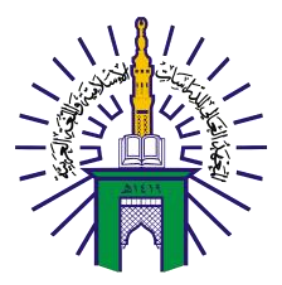

\section{BUSTANUL FUQAHA: \\ JURNAL BIDANG HUKUM ISLAM \\ Vol. 2 No. 2 (2021):Hal. 336-347 \\ EISSN: 2723-6021 \\ Website: https://journal.stiba.ac.id}

peduli terhadap semut. Dikisahkan bahwa kemudiaan Nabi Sulaiman Alaihisalaam dan bala tentaranya berhenti agar para semut masuk ke dalam sarangnya terlebih dahulu, karena beliau tak mau menginjak seekor pun, dan agar tidak melukai semut-semut itu. Adapun ihwal memanfaatkan binatang langka untuk bahan pengobatan, maka dalam syariat Islam (fiqih) mengklasifikasi bahan obat yang akan digunakan, yaitu bahan obat yang terbuat dari barang yang tidak dilarang dikomsumsi, atau bahan obat yang mubah (boleh), juga tanpa ada khilaf di antara para ulama ${ }^{23}$.

\section{Pandangan Para Ulama Terhadap Hewan Percobaan}

Dalam Islam, apakah diperbolehkan menggunakan suatu barang yang tidak diperbolehkan atau diharamkan mengkomsumsinya atau dijadikan sebagai obat, seperti misalnya ular, tikus, atau empedu beruang ${ }^{24}$. Menurut Hasyiyah al-Qolyubi: "Diperbolehkan bagi seseorang untuk menggunakan "Jasa hewan," walaupun bukan semestinya (akan tetapi dianggap baik menurut kebiasaannya), seperti kuda untuk dibuat alat pengangkut, dan sapi untuk ditunggangi." Dengan memperhatikan penjelasan tersebut, maka diperbolehkan bagi seseorang untuk mengurung hewan, walaupun hanya untuk mendengarkan "Merdu" suarannya, atau untuk hiburan, atau memerihara seekor anjing, dengan catatan ada "hajat" kebutuhan (untuk hal tersebut, seperti dijadikan penjaga), akan tetapi harus mencukupi makanan (kebutuhannya).

\section{Hukum yang Membolehkan Hewan Percobaan}

Hewan tidak harus dianggap sebagai properti dan penggunaan hewan oleh manusia tidak dapat diterima. Dengan demikian, beberapa pendukung hak-hak binatang berpendapat bahwa persepsi penerapan kesejahteraan hewan harus dilaksanakan dengan lebih baik dalam memfasilitasi dan peningkatan eksploitasi hewan. Oleh karena itu, beberapa pihak berwenang memperlakukan hak kesejahteraan hewan dan binatang sebagai dua posisi yang berlawanan. Orang-orang memandang kepedulian terhadap kesejahteraan hewan sebagai langkah-langkah tambahan terhadap hak-hak binatang. Di sisi lain, posisi yang paling paling banyak diterima di dunia Barat adalah posisi yang secara moral dapat diterima bagi manusia dalam menggunakan hewan, asalkan efek buruk pada kesejahteraan hewan dapat diminimalkan sebanyak mungkin.

Penerapan hukum terhadap pelangggaran kesejahteraan hewan cenderung tidak hanya didasarkan pada kekhawatiran kesejahteraannya, akan tetapi keyakinan bahwa perilaku seperti memiliki dampak terhadap pengobatan manusia lain oleh pelaku hewan, argumen lain terhadap kekejaman terhadap hewan didasarkan pada estetika. Dalam konteks penelitian hewan, banyak organisasi ilmiah percaya bahwa peningkatan kesejahteraan hewan akan memberikan hasil ilmiah yang lebih optimal.

Jika hewan di laboratorium menderita stres atau sakit, secara negatif dapat mempengaruhi hasil penelitian. Berkenaan dengan itu, diriwayatkan oleh Ibnu Abbas radhiyallahuanhu bahwa suatu hari Rasulullah saw. melewati seekor keledai yang dicap

${ }^{23}$ Ranuwijaya, Utang. "Keharaman Hewan Dalam Perspektif Al-Qur'an Dan Hadits." Al Qalam 22.3 (2005), h. 471

${ }^{24}$ Hasyiyah al-Qolyubi, al- Maktabah al-Syamilah al-Ishdaru al-Tsany (cet:ll al-Maktabah alSyamilah, 1952 M) h. 86. 
pada wajahnya dengan besi panas sehingga menjadi tanda yang tidak hilang seumur hidup, maka kontan beliau saw. menegaskan bahwa perbuatan itu akan melahirkan laknat dari Allah saw., beliau bersabda, yang artinya: "Allah melaknat orang yang memberinya cap" (HR. Muslim) ${ }^{2526}$.

Hadis ini menegaskan bahwa melukai satwa pada bagian yang sensitif dan menyebabkan cacat adalah dilarang. Islam mengatur pemanfaatan terhadap segala sesuatu yang ada di bumi, Ini adalah bukti bahwa Islam begitu memperhatikan aspek kesejahteraan binatang, tidak ada sedikitpun bagi umat Islam untuk menyakiti binatang meskipun pada akhirnya binatang itu akan dimakan.

Pentingnya etika di dalam dunia kedokteran, etika kedokteran juga sangat berhubungan dengan hukum, hampir di semua negara ada hukum yang secara khusus mengatur bagaimana dokter harus bertindak berhubungan dengan masalah etika dalam perawatan pasien dan penelitian. Etika membuat standar perilaku yang lebih tinggi dibanding hukum yang menyuruh melakukan tindakan yang tidak etis, di mana hukum juga berbeda-beda untuk tiap negara, sedangkan etika dapat diterapkan tampa melihat batas Negara.

Prinsip dasar penelitian sudah ditemukan, banyak peneliti terkemuka pada abad ke-19 dan 20 melakukan penelitian terhadap pasien. Walaupun sudah ada etika penelitian yang disepakati pada abad ke-20 namun tidak dapat mencegah dokter Nazi untuk melakukan penelitian terhadap pasien yang jelas bertentangan dengan hak asasi manusia. Setelah Perang Dunia II beberapa dokter tersebut disidang dan terbukti dengan pengadilan khusus di Nuremberg, Jerman, dan dasar dari pengadilan dikenal sebagai Nuremberg Code, yang merupakan salah satu dokumen terpenting dalam etika penelitian modern ${ }^{27}$.

\section{Analisis Percobaan Kedokteran terhadap Hewan Hidup dalam Perspektif Hukum Islam.}

Penelitian dengan melibatkan pemanfaatan hewan terbukti telah menjadi landasan yang baik bagi pengembangan dan kemajuan bidang ilmu medis selama lebih dari dua abab ini. Penggunaan hewan dalam penelitian hingga saat ini masih menimbulkan pro dan kontra karena beberapa prosedur diyakini dapat menyebabkan penderitaan pada hewan, walaupun beberapa undang-undang dan aturan mengenai kesejahteraan hewan di dunia telah berdampak pada pengurangan jumlah hewan yang boleh digunakan dalam penelitian biomedis serta telah memperbaiki dan mengurangi rasa nyeri/penderitaan, masih banyak pertanyaan mengenai etika sehubungan dengan cara-cara pengggunaan hewan dalam penelitiaan biomedis.

Etika penelitian mengggunakan hewan tidak hanya diperuntuhkan bagi penelitian yang bertujuan memahami penyakit manusia saja, namun digunakan pula dalam penelitian lainnya yang berkenaan dengan kepentingan hewan itu sendiri, termasuk studi

${ }^{25}$ Al-imam Abul Husain Muslim bin Al-Hajjaj Al-qusayri An-Naisaburi, Kitab Shahih Muslim, (Maktabah Syamilaah: Riyadh), Bab nahyi an- dhorib Hayawan fii wajhih, No. Hadits 2117, Juz 03, Shofahah. 1673

${ }^{26}$ Yunanda, Rifki. Fauna dalam Perspektif Al-Qur'an (Studi Tafsir Ilmi Kemenag LIPI). Diss. UIN Raden Intan Lampung, 2019.

${ }^{27}$ PSKI Fakultas Kedokteran UMY, Medical Ethics Manual, (Yogyakarta: 2005), h.13-18 


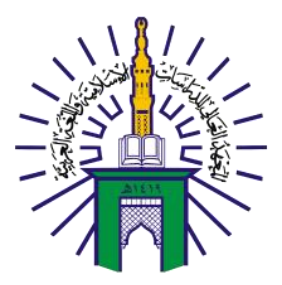

\section{BUSTANUL FUQAHA: \\ JURNAL BIDANG HUKUM ISLAM \\ Vol. 2 No. 2 (2021):Hal. 336-347 \\ EISSN: 2723-6021 \\ Website: https://journal.stiba.ac.id}

\section{BUSTANUL FUQAHA}

Jurnal Bidang Hukum Islam

tentang penyakit hewan, penggunaan hewan untuk menguji ke mana produk rumah tangga, bahkan kimia yang digunakan dalam proses dan distibusi kosmetik yang merusak manusia. Penanganan dan pengendalian hewan untuk penelitian kesehatan merupakan faktor yang sangat penting baik dari aspek kepentingan ilmiah maupun kesejahteraan hewan. Percobaan pertanian yang bertujuan menghasilkan hewan sebagai bahan pangan serta pengggunaan hewan dalam percobaan yang dilakukan dengan landasan uji coba ${ }^{28}$.

Etika penelitiaan menggunakan hewan juga mengcakup pertimbangan pertanyaan yang berhubungan dengan perawatan hewan. Ketika digunakan atau ketika hewan tidak dalam prosedur penelitiaan, serta pengaruh fisiologi dan tingkah laku hewan selama penelitiaan dan penanganan, sebagai upaya meningkatkan kesejahteraan hewan dalam penelitiaan yang melibatkan hewan, konsep $3 \mathrm{R}$ (Replace, Reduce, Refine) digunakan sebagai sarana untuk pemperlakukan hewan secara manusiawi yang diperlukan untuk melindungi hewan-hewan tersebut dari rasa ketidaknyamanan ${ }^{29}$ ataupun penggunaan hewan dalam jumlah berlebih, dalam hal ini diperlukan suatu komisi yang mengawasi dan mengatur aktivitas atau prosedur yang berkaitan dengan penggunaan hewan ${ }^{30}$.

Pandangan umum Islam terhadap pemanfaatan binatang, mausia sebagai pemimpin di bumi "Kholifatul fi al-Ardy" mempunyai beberapa wewenang dan tanggung jawab yang diberikan oleh Allah swt., berkaitan erat dan juga karena manusia mempunyai wewenang untuk memanfaatkan hasil bumi serta segala sesuatu yang hidup diatasnya seprti tumbuhtumbuhan dan binatang yang telah disediakan secara gratis oleh Allah swt. maka manusia mempunyai hak untuk memanfaatkannya. Namun, yang perlu diingat adalah manusia juga harus bertanggung jawab dan tetap memeliharanya, pemanfaatan tersebut bukan berarti bahwa manusia boleh memanfaatkan sekehendak hatinya, namun perlu pemanfaatan yang bertanggung jawab dan berkelanjutan.

Syariat tidak membahas secara langsung isu tentang eksperimen pada binatang, namun fikih merupakan ilmu pengetahuaan yang menuntut umat Islam dalam menentukan mana keputusan manusia yang berhubungan dengan isu-isu kontemporer yang dapat dibenarkan dan mana yang tidak baik. Dalam hal ini dinyatakan bahwa banyaknya suatu permasalahan yang timbul atau menimbulkan tindakan tertentu, yang dimotivasi oleh keterpaksaan (al-Dharurah) dalam rangka melindungi salah satu dari kepentingankepentingan, maka secara kondisional dapat hal itu dibenarkan. Selain itu, dapat pula dikatakan bahwa jika eksperimen pada hewan dapat dilaksanakan dengan tujuan memperoleh pengetahuan yang benar-benar bermanfaat bagi kelestariaan hidup manusia dan hewan, maka eksperimen tersebut dapat disetujui, namun apa yang diistilahkan sebagai kepentingan (manusia) yang mendesak (al-Maslahah al-Dharuriyyah) ini lebih jauh dibatasi oleh prinsip-prinsip umum fikih, hal itu ditengarai bahwa:

1. Sesuatu yang dapat membawa kepada hal-hal yang diharamkan, maka hukumnya haram.

${ }^{28}$ Pamungkas Joko, dkk., Prosiding konferensi ilmiah veteriner nasional (Palembang KIVNAS, 2014), h.218

${ }^{29}$ Citra Nur, Mutiarahmi, Tyagita Hartady, and Ronny Lesmana. "Kajian Pustaka: Penggunaan Mencit Sebagai Hewan Coba di Laboratorium yang Mengacu pada Prinsip Kesejahteraan Hewan." Jurnal Indonesia Medicus Veterinus 10 (2021).

${ }^{30}$ Mohammad Na' fi, Islam Peduli Terhadap Satwa h. 5. 


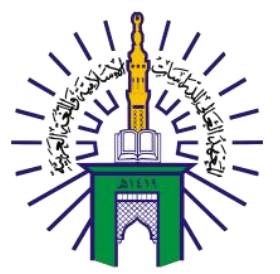

\section{BUSTANUL FUQAHA: \\ JURNAL BIDANG HUKUM ISLAM \\ Vol. 2 No. 2 (2021):Hal. 336-347 \\ EISSN: 2723-6021 \\ Website: https://journal.stiba.ac.id}

2. Seseorang yang terpaksa harus memilih antara dua hal yang buruk, maka ia harus memilih yang lebih kecil keburukannya untuk mencegah keburukan yang lebih besar.

3. Sesuatu yang dihalalkan karena alasan tertentu akan menjadi tidak halal jika alasan kehalalanya itu tidak ada lagi.

4. Menggunakan berbagai pilihan untuk hal-hal yang tidak ada ketentuannya.

\section{KESIMPULAN}

Kajian ini berupaya untuk mengetahui hukum percobaan kedokteran terhadap hewan hidup dalam perspektif fikih kontemporer, serta mengetahui pendapat para ulama dalam memahami masalah tersebut. Hasil penelitian menunjukkan bahwa sebagian ulama membolehkan penggunaan hewan dalam suatu percobaan. Namun, sebagian ulama tidak membolehkan penggunaannya tanpa mengetahui etika dalam percobaan. Alasannya bahwa hal ini pernah ada di bidang kesehatan pada masa Rasulullah saw. Adapun jika penggunaannya dilakukan tanpa ada kebutuhan yang mendesak, maka hukumnya tidak diperbolehkan.

\section{DAFTAR PUSTAKA}

Al-Qolyubi, Hasyiyah. Al-Maktabah al-Syamilah al-Ishdaru al-Thany, vol. 14 Cet. 11; alMaktabah al-Syamilah $195 \mathrm{M}$.

An-Naisaburi, Al-imam Abul Husain Muslim bin Al-Hajjaj Al-Qusayri. Kitab Shahih Muslim, (Maktabah Syamilaah: Riyadh), Bab nahyi an- dhorib Hayawan fii wajhih, No. Hadits 2117, Juz 03, Shofahah. 1673

Dewi, Fitriya N, \& J Mark Cline. "Satwa Primata sebagai Hewan Model Studi Biologi dan Kanker Payudara." Jurnal Ilmiah Veteriner Nasional 13 (2014), h. 114.

Endi Ridwan, "Etika Pemanfaatan Hewan Percobaan Penelitian Kesehatan" J Indon Med Assoc. 63, no. 3 (Maret, 2013).

Iskandriati, Diah, Dondin Sajuthi, \& Joko Pamungkas. "Pemanfaatan Hewan dalam Pengujuan dan Model Penyakit Manusia." Jurnal Ilmiah Veteriner Nasional 13 (2014): 112.

Jumrodah, "Pandangan Aksiologi terhadap Bioetika dalam Memanfaatkan hewan Coba (Animal Research) di Laborstorium” JURNAL IAIN PALANGKARAYA 2, No. 1 (Februari, 2017)

Joko, Pamungkas, dkk., Prosiding Konferensi Ilmiah Veteriner Nasional.

Kurniawan, Shahdevi Nandar, and Neila Raisa. Penggunaan Hewan Coba pada Penelitian di Bidang Neurologi. Universitas Brawijaya Press, 2018.

Mutiarahmi, Citra Nur, Tyagita Hartady, and Ronny Lesmana. "Kajian Pustaka: Penggunaan Mencit Sebagai Hewan Coba di Laboratorium yang Mengacu pada Prinsip Kesejahteraan Hewan." Jurnal Indonesia Medicus Veterinus 10 (2021).

Mohammad, Na'fi , Islam Peduli Terhadap Satwa, Cet: 1, Malang, 2010.

Nainu, Firzan. "Penggunaan Drosophila melanogaster sebagai organisme model dalam penemuan obat." Jurnal Farmasi Galenika (Galenika Journal of Pharmacy)(eJournal) 4.1 (2018): 50-67.

Nugroho, Agung Endro. "Hewan percobaan diabetes mellitus: patologi dan mekanisme aksi diabetogenik." Biodiversitas 7.4 (2006): 378-382.

Palembang KIVNAS, 2014. 


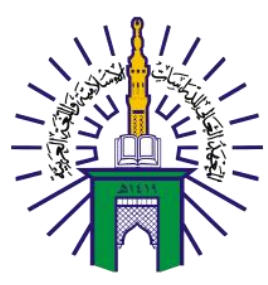

\section{BUSTANUL FUQAHA: \\ JURNAL BIDANG HUKUM ISLAM \\ Vol. 2 No. 2 (2021):Hal. 336-347 \\ EISSN: 2723-6021 \\ Website: https://journal.stiba.ac.id}

Pamungkas, Joko, Diah Iskandriati, Maryati Surya, \& Dondin Sajuthi. "Peran Komisi Etik dalam Kegiatan Penelitian, Pengujuan dan Pendidikan." Jurnal Ilmiah Veteriner Nasional 13 (2014): 107.Diss. UIN Raden Intan Lampung, 2019.

PSKI Fakultas Kedokteran UMY, Medical Ethics Manual, Yogyakarta : 2005

Setijono, Marcellino Mardanung. "Mencit (Mus musculus) sebagai hewan percobaan." (1985).

Ranuwijaya, Utang. "Keharaman Hewan Dalam Perspektif Al-Qur'an Dan Hadits." Al Qalam 22.3 (2005): 457-475.

Yunanda, Rifki. Fauna dalam Perspektif Al-Qur'an (Studi Tafsir Ilmi Kemenag LIPI).

Winoto, Imelda L. "Penanganan dan Pengendalian Hewan Laboratorium." Jurnal Ilmiah Veteriner Nasional 13 (2014): 108-124.

\section{Sumber Online}

https://tafsirq.com/2-al-baqarah/ayat-29 (Diakses 18/08/2021)

https://tafsirq.com/45-al-jasiyah/ayat-13 (Diakses 18/08/2021) 